\title{
INVENTÁRIO DO AMBIENTE NATURAL DO LITORAL MÉDIO DO RIO GRANDE DO SUL COMO AUXÍLIO PARA ANÁLISE AMBIENTAL
}

\author{
Ana Rita Oliveira Hahn ${ }^{(\mathrm{a})}$, Luiz Felipe Velho ${ }^{(\mathrm{b})}$, Iran Carlos Stalliviere Corrêa ${ }^{(\mathrm{c})}$, Jair \\ Weschenfelder ${ }^{(\mathrm{d})}$
}

(a) Instituto de Geociências, Universidade Federal do Rio Grande do Sul, ritageohahn@ gmail.com

(b) InstitutoFederal de Educação, Ciência e Tecnologia do Rio Grande do Sul, ritageohahn@ @mail.com

(c) Instituto de Geociências, Universidade Federal do Rio Grande do Sul, iran.correa@ufrgs.br

(d) Instituto de Geociências, Universidade Federal do Rio Grande do Sul, jair.weschenfelder@ufrgs.br

\section{Eixo: DINÂMICA E GESTÃO DE ZONAS COSTEIRAS}

\begin{abstract}
Resumo
O presente trabalho tem como área de estudo o Litoral Médio da Planície Costeira do Rio Grande do Sul (PCRGS) e objetiva desenvolver um compêndio das pesquisas científicas realizadas, até os dias atuais, sobre essa região da costa meridional do Brasil. Comparado ao setor costeiro com maior volume de estudos científicos, que corresponde ao Litoral Norte, o Litoral Médio dispõe de eficientes pesquisas, porém menos numerosas. Durante a compilação de estudos proposta, são referenciadas as discussões iniciais referentes à geologia e geomorfologia da costa do RS ocorridas na década de 1960, as pesquisas seguintes sobre sua caracterização evolutiva e geomorfológica e, por fim, os apontamentos científicos mais recentes sobre o setor costeiro em questão. A explanação sobre o arcabouço teórico em questão possibilita tanto a visualização do contexto regional, quanto a compreensão em termos locais sobre o ambiente natural do Litoral Médio do RS.
\end{abstract}

Palavras chave: Ambiente Costeiro, Dinâmica Costeira, Planície Costeira do Rio Grande do Sul, Compêndio de Estudos.

\section{Introdução}

A costa do Rio Grande do Sul apresenta-se como uma extensa planície arenosa desenvolvida durante as variações glacioeustáticas do nível médio do mar ocorridas no Pleistoceno e no Holoceno, ou seja, entre 2 milhões e 12 mil anos Antes do Presente (AP) aproximadamente (VILLWOCK e TOMAZELLI, 1995). As regressões e transgressões marinhas, resultantes dessas variações, ocorreram durante períodos glaciais e interglaciais produzidos pela alternância cíclica, respectivamente, de períodos mais frios e mais quentes ao longo do período Quaternário (CROWLEY e NORTH, 1991).

Essa dinâmica glacioeustática foi responsável por modelar a larga faixa arenosa de, aproximadamente, $640 \mathrm{~km}$ que compreendem a Planície Costeira do Rio Grande do Sul (PCRGS). O extenso ambiente de interface entre a costa mais meridional do Brasil e o oceano Atlântico Sul pode, ainda, ser dividido em três setores distintos: Litoral Norte, Litoral Médio e Litoral Sul do RS. 


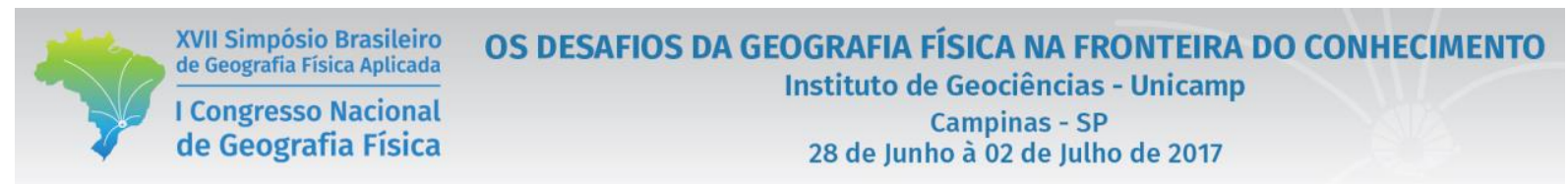

Apesar do ambiente deposicional que caracteriza a barreira arenosa correspondente à PCRGS ocorrer, praticamente, de forma contínua ao longo da costa do Estado, esses três setores distintos da barreira diferenciam-se, entre outros elementos, devido a características evolutivas específicas. Segundo Dillenburg et al. (2007), ao longo de sua evolução durante o Holoceno Médio e Tardio (desde 7 mil anos AP aproximadamente) essa barreira arenosa diferenciou-se em setores onde predominou a sua regressão em relação ao nível médio do mar, em áreas onde houve o predomínio de transgressão no comportamento evolutivo da barreira e, por fim, em porções onde o comportamento predominante foi agradacional ou estacionário.

De maneira que uma melhor visualização e, por conseguinte, compreensão da dinâmica natural do meio físico do setor médio da PCRGS sejam possibilitadas, o presente trabalho objetiva elaborar um inventário acerca dessa área da costa do RS, realizando-se um compêndio dos estudos outrora desenvolvidos sobre ela.

\section{Estudos sobre o Ambiente Natural do Litoral Médio do Rio Grande do Sul}

O Litoral Médio do RS situa-se, aproximadamente, entre as coordenadas $30^{\circ} 08^{\prime} 00^{\prime \prime}$ e $32^{\circ} 20^{\prime} 00^{\prime \prime}$ de latitude Sul e entre 49 $00^{\prime} 00^{\prime}$ e $53^{\circ} 30^{\prime} 00^{\prime}$ de longitude Oeste, delimitado pelo município de Cidreira ao norte, como mostra a figura 1, e pela desembocadura da laguna dos Patos, em Rio Grande, ao sul.

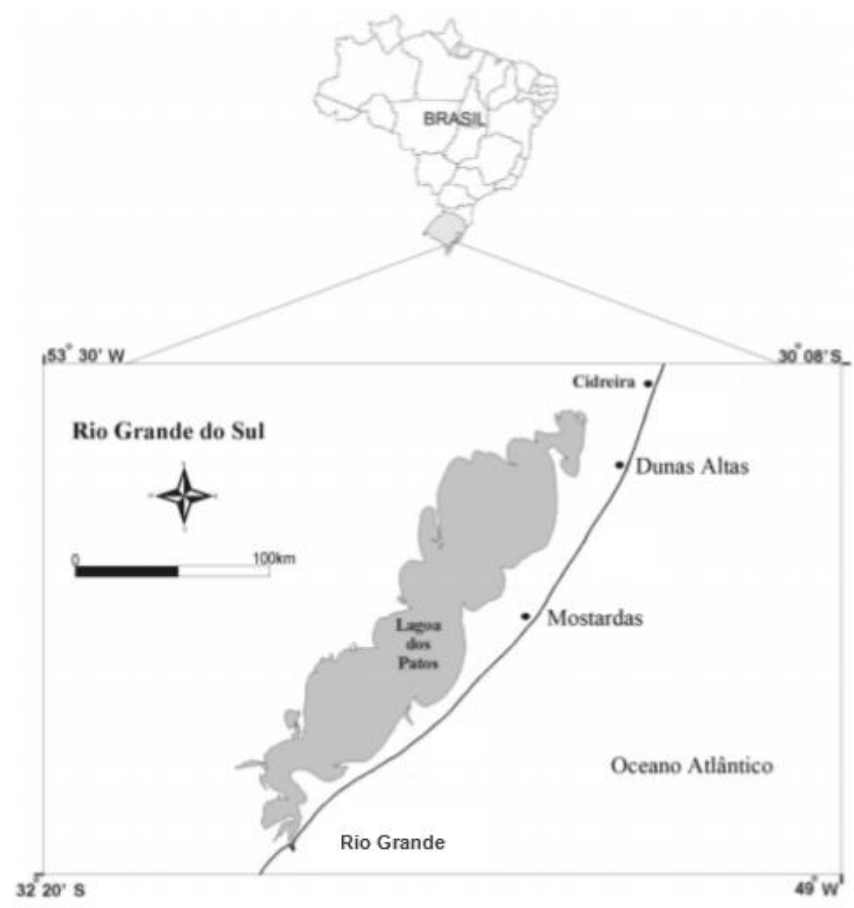

Figura 1: Localização do Litoral Médio do RS. Fonte: Modificado de Toldo Jr. et al., 2006. 
Entre as contribuições científicas iniciais que mencionaram o setor médio da PCRGS, podem ser citadas as de Morris (1963), Delaney (1965), Martins (1967), Villwock (1972), Soliani Jr. (1973) e Corrêa (1986 e 1987). No estudo realizado por Carraro et al. (1974), a caracterização da costa meridional do Brasil como Planície Costeira foi utilizada durante a compartimentação geomorfológica do RS elaborada pelos autores. Dessa compartimentação, surgiram quatro províncias geomorfológicas: o Planalto, a Depressão Periférica, o Escudo Sul-Riograndense e a Planície Costeira.

A Província Costeira do RS, conforme denominação usada por Villwock (1984), corresponde a uma planície costeira e a uma plataforma continental onde coexiste uma linha de costa controlada pela interação entre taxa de suprimento sedimentar, taxa de soerguimento e/ou subsidência e variações do nível médio do mar (VILLWOCK, 1984). Nesse tipo de ambiente, onde a linha de costa varia espacial e temporalmente de acordo com a interação entre essas três variáveis, desenvolve-se uma interface entre os ecossistemas continentais, transicionais e marinhos muito característica dessa província.

Este mesmo estudo realizado por Villwock (1984) dividiu geomorfologicamente a Província Costeira do RS em dois setores: as Terras Baixas, que contemplam a PCRGS, e as Terras Altas, de onde são erodidos e transportados os sedimentos clásticos terrígenos que, depositados e retrabalhados em um novo ambiente morfodinâmico, irão compor a planície arenosa da costa do RS.

Nesta classificação da extensa planície arenosa correspondente à PCRGS, o autor subdividiu-a nos seguintes setores, de acordo com diferenciações em sua geomorfologia: Planície Aluvial Interna, Barreira das Lombas, Sistema Lagunar Guaíba-Gravataí, Barreira Múltipla Complexa e Sistema Lagunar PatosMirim (VILLWOCK, 1984). Esta subdivisão é feita de acordo com a dinâmica evolutiva de cada um desses subambientes e, consequentemente, conforme os processos morfodinâmicos atuantes sobre eles na atualidade.

Os subambientes identificados por Villwock (1984) estão inseridos em dois tipos de sistemas deposicionais desenvolvidos ao longo das oscilações climáticas ocorridas durante o Quaternário: o Sistema de Leques Aluviais, composto por rochas mais antigas, e o Sistema do Tipo Laguna-Barreira, sendo ambos esquematizados na figura 2. As oscilações entre períodos mais frios e mais quentes resultaram em regressões e transgressões marinhas, as quais provocaram respectivos avanços e recuos da linha de costa e, consequentemente, na formação desses dois tipos de registros deposicionais integrantes da paisagem atual da PCRGS. 

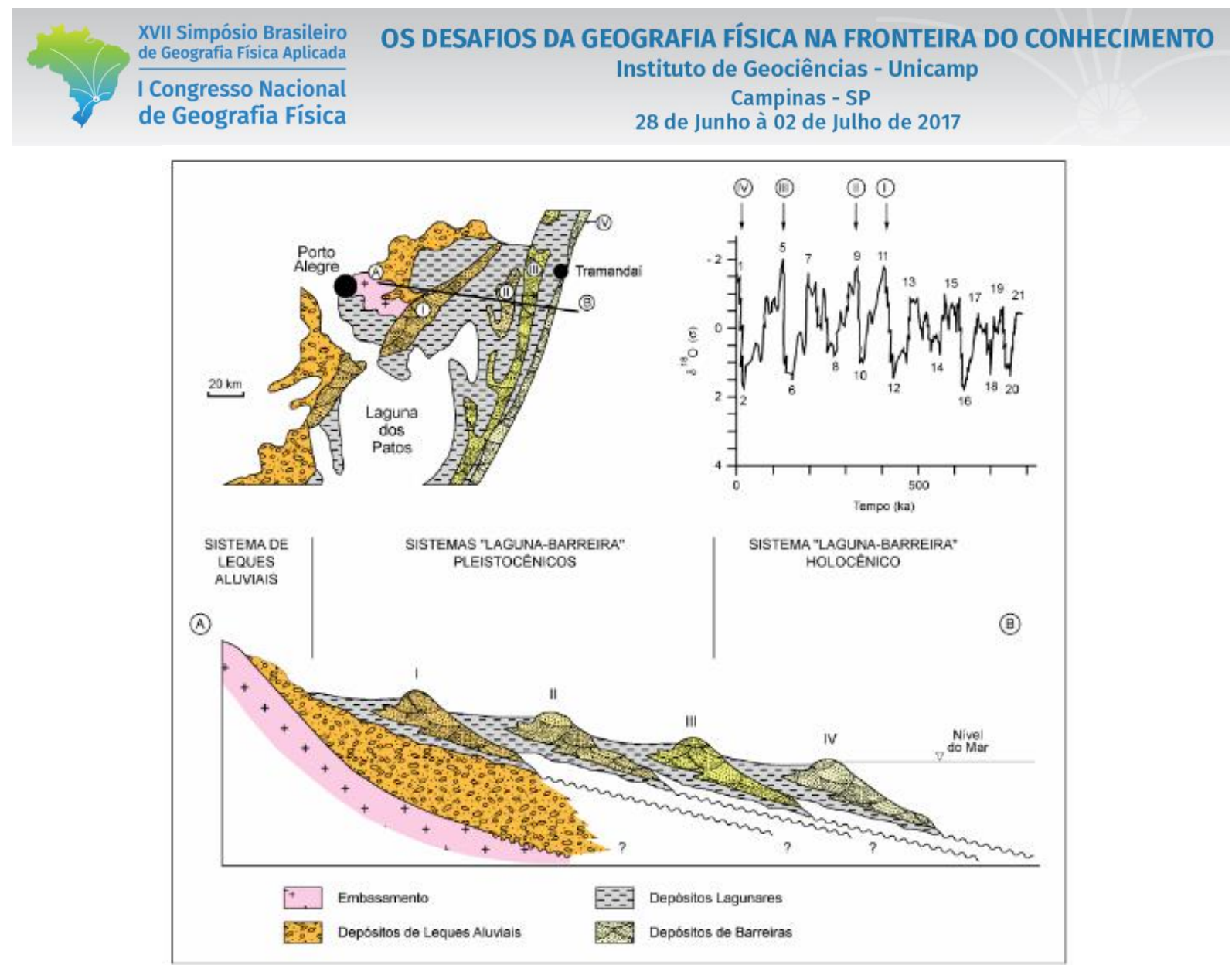

Figura 2: Perfil esquemático transversal aos sistemas deposicionais da PCRGS na latitude de Porto Alegre. As quatro barreiras são correlacionadas aos últimos maiores picos da curva isotópica de oxigênio. Fonte: Tomazelli e Villwock, 2000.

Os Sistemas do Tipo Laguna-Barreira são caracterizados por Dillenburg e Hesp (2009) como sistemas deposicionais que integram a geomorfologia das costas dominadas por ondas, como é o caso da costa do RS, desenvolvendo-se mundialmente em áreas onde o gradiente topográfico é suave e onde há abundância de sedimentos arenosos disponíveis. Segundo esses mesmos autores, a morfologia de uma barreira arenosa costeira é controlada, basicamente, pela relação entre as variações do nível médio do mar e o balanço local de sedimentos, o que resulta em uma barreira transgressiva ou regressiva.

Na PCRGS, quatro sistemas do tipo Laguna-Barreira, resultantes de variações do nível relativo do mar no decorrer das oscilações climáticas dos últimos 400 mil anos AP, foram preservados no registro deposicional (vide figura 2). Os subsistemas correspondentes às barreiras referem-se ao pico no qual chegou o nível do mar durante determinado evento de transgressão marinha, enquanto que os subsistemas correspondentes às planícies lagunares referem-se aos terrenos de backbarrier ou retrobarreira (VILLWOCK, 1984). 
O estudo de Villwock (1984) caracterizou, portanto, as bacias do rio Gravataí e o complexo do Guaíba como integrantes do Sistema Lagunar I, com o qual a Barreira das Lombas forma o Sistema LagunaBarreira mais antigo da PCRGS (com idade aproximada de 400 mil anos AP). O Sistema Laguna-Barreira II, formado há 325 mil anos aproximadamente, é constituído pela feição denominada Barreira Múltipla Complexa e pelos sistemas lagunares correspondentes à laguna dos Patos e à lagoa Mirim.

O Sistema Laguna-Barreira, de 120 mil anos AP aproximadamente, abrange pequenos tabuleiros arenosos constituintes do terraço marinho da Barreira III e alguns depósitos sedimentares associados ao Sistema Lagunar III, nos quais Soliani Jr. (1973) encontrou fósseis de mamíferos pleistocênicos. Por fim, o Sistema Laguna-Barreira IV, único dos quatro sistemas formado durante o Holoceno (aproximadamente, há 7 mil anos AP) abrange a extensa faixa de areia quartzosa que corresponde às praias atuais do RS.

De acordo com Dillenburg et al. (2007), a barreira holocênica que integra a PCRGS diferenciou-se ao longo da costa durante sua evolução iniciada no Holoceno Médio e Tardio, havendo segmentos costeiros em que se observa uma dinâmica regressiva da barreira e outros em que essa dinâmica mostra-se transgressiva, além de ocorrerem trechos em que a feição apresenta uma natureza estacionária. Essa diferenciação da barreira holocênica em tipologias de acordo com sua natureza evolutiva e dinâmica deve-se a respostas distintas a gradientes diferentes de ondas, controlados pela topografia que antecede a última transgressão pós-glacial, e a balanços sedimentares também diferenciados (DILLENBURG et al., 2000).

Os estudos de Dillenburg et al. (2000, 2003 e 2007) identificaram que os setores da barreira holocênica da PCRGS nos quais a tipologia é regressiva situam-se em segmentos costeiros "ligeiramente embaiados", ou seja, com suaves reentrâncias na costa. Nos setores onde a tipologia da barreira é transgressiva ou estacionária (agradacional), esses estudos observaram que a linha de costa apresenta uma configuração suavemente saliente em direção ao oceano, formando as denominadas "projeções costeiras".

Segundo as pesquisas supracitadas, a configuração espacial da linha de costa do RS apresenta esses embaiamentos e projeções devido a existência de gradientes de potência de onda ao longo da costa, os quais estão presentes desde os estágios iniciais de formação da barreira, ocorridos há 7 mil anos AP aproximadamente. Conforme Dillenburg et al. (2003) e de acordo com o que mostra a figura 3, a energia das ondas na costa do RS cresce da parte central dos embaiamentos para as porções mais salientes das projeções costeiras, e a região correspondente ao Litoral Médio abrange um setor da barreira onde ocorre uma suave projeção da linha de costa (vide figura 1). 

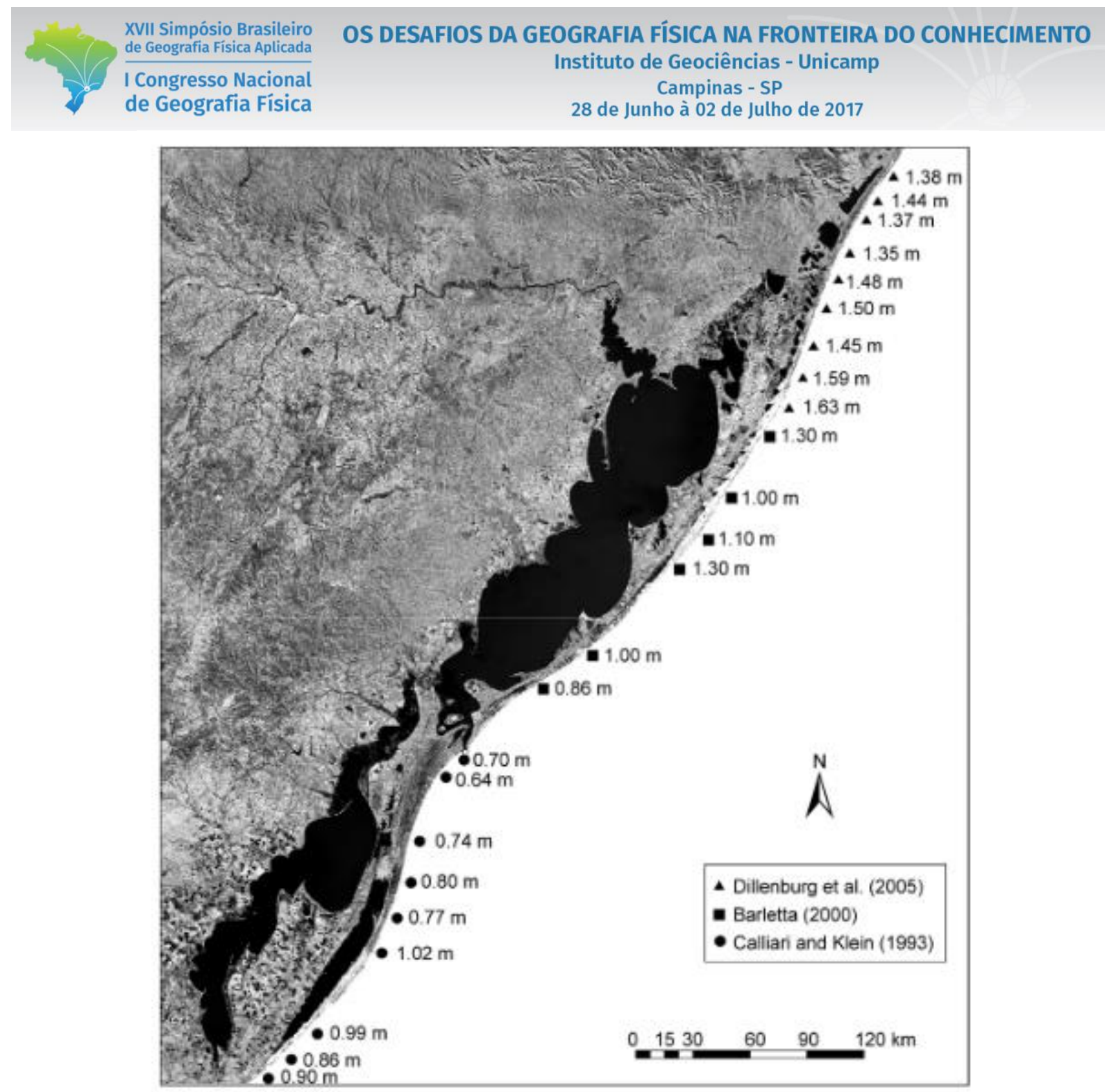

Figura 3: Setores ao longo das projeções e embaiamentos da costa do RS com seus respectivos valores de altura significativa de onda (H1/3) segundo estudos de Calliari e Klein (1993), Barletta (2000) e Dillenburg et al. (2005). Fonte: Dillenburg e Hesp (2009).

A localização geográfica do Litoral Médio nesse setor costeiro, de acordo com a compreensão que esses estudos possibilitam, condiciona-o à ação de regimes de onda com maiores potências. De fato, Dillenburg et al. (2007) identificou que as dunas frontais mais altas da costa do RS estão situadas nesta região, mais precisamente no balneário de Dunas Altas (entre 10 e 12 metros de altura), localizado na porção norte da projeção costeira em questão (vide figura 1).

A correlação entre o desenvolvimento excepcional do cordão de dunas frontal em Dunas Altas e em outros trechos do Litoral Médio do RS e entre a natureza evolutiva e morfodinâmica desse setor da barreira foi analisada por Dillenburg et al. (2004 e 2005), sendo reiterada por Dillenburg et al. (2007). 
Com o estudo de 2005, no qual a natureza estacionária ou agradacional do setor de Dunas Altas foi identificada, e com os apontamentos de 2007 que a confirmaram, estabeleceu-se um elo entre essa tipologia e o expressivo desenvolvimento vertical das dunas frontais no local, oriundos da alternância entre períodos de maior progradação (regressão) da barreira e períodos de maior retrogradação (transgressão) da mesma, havendo uma pequena resultante de progradação (DILLENBURG et al. 2005 e 2007).

De acordo com o estudo geológico e geomorfológico das barreiras holocênicas do Brasil efetuado por Dillenburg e Hesp (2009), a barreira arenosa na qual está situado o Litoral Médio do RS desenvolveu-se de maneira semelhante aos demais setores da PCRGS, ou seja, através de variações da linha de costa controladas por glacioeustasia. No estudo realizado pelos autores, entretanto, a barreira holocênica da costa do RS é compartimentada conforme variações locais na sua natureza evolutiva e morfodinâmica atual, como mostra a figura 4, sendo dividida em cinco setores: de Torres à Tramandaí (1), de Tramandaí à Mostardas (2), de Mostardas à Estreito (3), de Estreito à Verga (4) e de Verga à Chuí (5). 

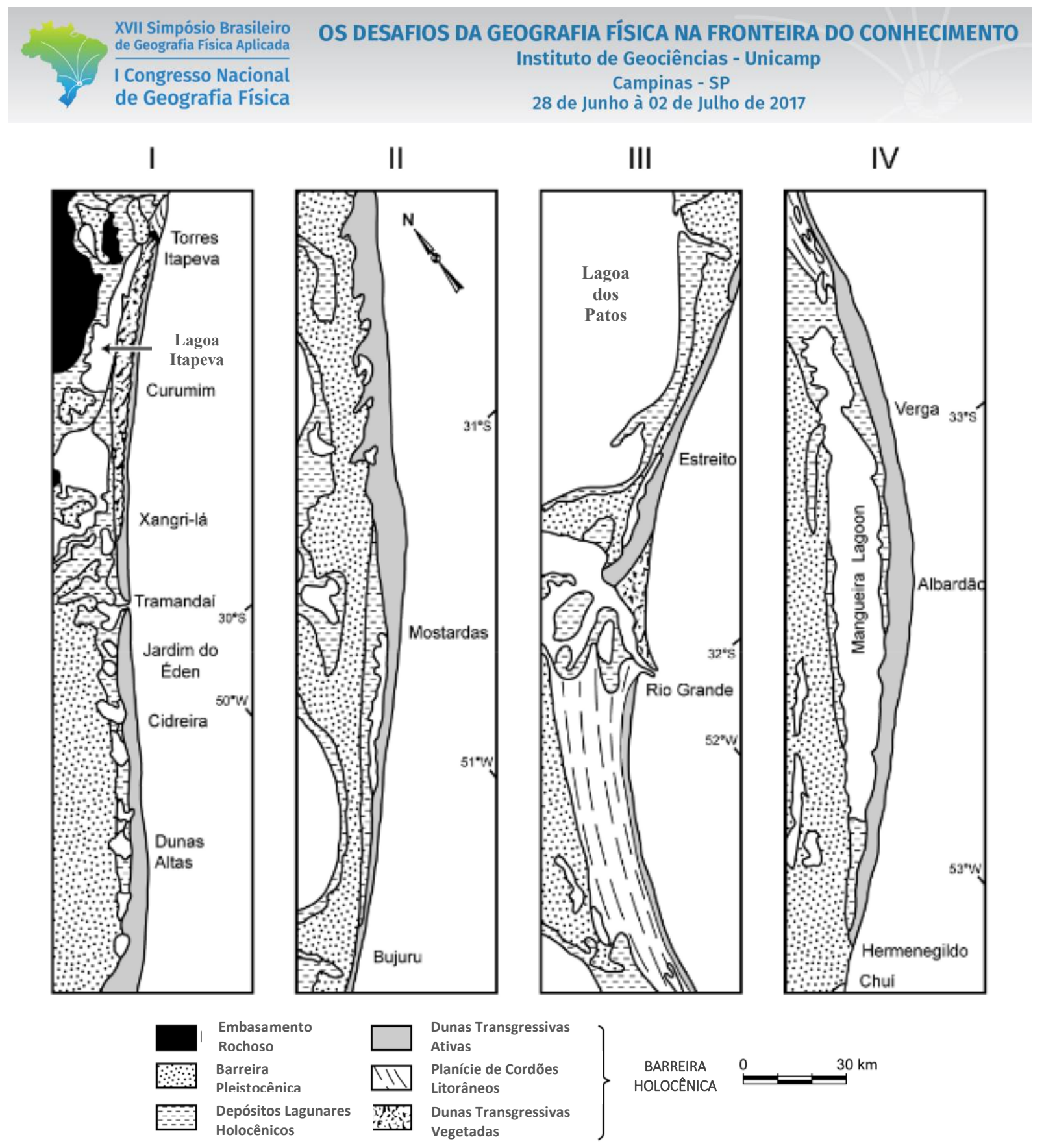

Figura 4: Barreiras pleistocênicas e holocênicas ao longo da costa do RS, de Torres ao Chuí. São mostrados o setor costeiro mais ao norte (I) e, progressivamente, os setores mais ao sul (II, III e IV). São mostradas, também, distintas feições geomorfológicas integrantes dos segmentos costeiros na legenda. Reinterpretação de Dillenburg et al. (2000) e modificado de Hesp et al. (2005). Fonte: Dillenburg e Hesp (2009).

O Litoral Médio da PCRGS é contemplado por uma porção do setor que se estende de Tramandaí à Mostardas (II) e do setor de Mostardas à Estreito (III), havendo uma pequena porção que se extende de Estreito até a desembocadura da laguna dos Patos em Rio Grande (início da região denominada Litoral Sul). A maior parte desses dois trechos (II e III) situa-se em um segmento convexo do alinhamento costeiro do RS, ocorrendo projeção da linha de costa em direção ao oceano nesse setor (vide figura 4) e, 
por conseguinte, exposição dessa área a valores mais altos de energia de onda (vide os valores de altura significativa de onda na figura 3 ).

Conforme Dillenburg et al. (2000), o setor médio da barreira holocênica do RS, em função de ter sido desenvolvido sobre um segmento onde a inflexão costeira forma uma projeção para o oceano, situa-se sobre uma barreira mais estreita e de natureza transgressiva. Inclusive, há áreas do Litoral Médio do RS onde ocorre exposição de lamas lagunares e de turfas holocênicas na praia oceânica, segundo estudo efetuado por Tomazelli et al. (1998), além de significativas concentrações de minerais pesados, como os afloramentos na região de Bojuru (DILLENBURG et al., 2004).

Portanto, apesar da área onde se localiza o balneário Dunas Altas, inserida no setor II da barreira holocênica, situar-se sobre uma barreira arenosa de tipologia estacionária ou agradacional, as demais porções do Litoral Médio do RS (inseridas no setor III, de Mostardas à Estreito) assentam sobre uma barreira costeira de natureza transgressiva (DILLENBURG e HESP, 2009). As dunas verticalmente protuberantes que compõem o cordão arenoso frontal da praia de Dunas Altas, inclusive, interligam-se com extensos campos de dunas transgressivos que ocupam tanto o setor II quanto o setor III da barreira holocênica, sendo o trecho costeiro mais longo do RS onde uma barreira arenosa transgressiva coexiste com um campo eólico transgressivo de grande extensão, de acordo com os autores.

Apesar do significativo desenvolvimento dos depósitos eólicos frontais e transgressivos presente no Litoral Médio do RS, extensas zonas de erosão coexistem com esses setores de áreas estáveis e de progradação costeira. Nos estudos realizados por Toldo Jr. et al. (2006), Absalonsen e Toldo Jr (2007) e Marchi da Motta et al. (2015), diferentes segmentos com um balanço negativo de sedimentos no Litoral Médio foram identificados, os quais resultam da natureza transgressiva de maior parte da barreira e da maior energia com que o trem de ondas incide nesse setor ao longo do ano.

O predomínio de áreas com um balanço sedimentar estável e o aumento de zonas de progradação da linha de praia no Litoral Médio, como é o caso observado em Dunas Altas por Dillenburg et al. (2000, 2003 e 2007) e, por fim, por Toldo Jr. et al. (2006) e Absalonsen e Toldo Jr (2007), deve-se à influência da inflexão de, aproximadamente, $11^{\circ}$ no alinhamento da linha de praia existente na região de Mostardas (TOLDO JR. et al. 2006, ABSALONSEN e TOLDO JR. 2007). Conforme esses dois últimos estudos, a mudança local no ângulo de orientação da costa ocasiona um "engarrafamento", ao sul dessa inflexão, da deriva litorânea de sedimentos (da qual a resultante é de sul para norte na costa do RS), provocando deposição sedimentar em função da redução da energia de incidência das ondas e alargamento do estoque subaquoso na região de Dunas Altas. 
O "engarrafamento" da deriva litorânea de sedimentos ao sul da inflexão costeira, situada na região de Mostardas, proporciona uma redução do transporte sedimentar líquido de sul para norte em $20 \%$ na praia de Mostardas e em 35\% na praia de dunas Altas (TOLDO JR. et al., 2006). Conforme estes autores, o aumento volumétrico do estoque de sedimentos subaquoso nessas duas praias passa de seus valores médios de $1 \mathrm{~km}$ para mais de $3 \mathrm{~km}$, observando-se um consequente incremento no volume de areia dos campos de dunas frontais e transgressivos nessa região devido a esse estoque subaquoso também alimentar as dunas.

Os estudos acerca do clima do Litoral Médio do RS caracterizam-se na análise da relação entre o regime de ventos atuante na região e a geomorfologia eólica com Tomazelli (1990 e 1993), Tomazelli e Villwock (1991) e Tomazelli et al. (2000); no regime de precipitação pluvial sob o qual o Parque Nacional da Lagoa do Peixe (PNLP), unidade de conservação situada na região de Mostardas, está inserido (PLÁ, 2004) e na relação entre o volume de precipitação e o potencial local de transporte de areia pelo vento (MARTINHO et al., 2009). Identificou-se um padrão climático semelhante nos trabalhos, o qual apresenta um regime de chuvas abundante ao longo do ano, mas com um incremento pluviométrico no inverno devido à passagem da Frente Polar Atlântica (FPA), e a preponderância anual dos ventos de Nordeste, advindos do Anticiclone do Atlântico Sul.

\section{Considerações sobre o Ambiente Natural do Litoral Médio do Rio Grande do Sul a partir da Compilação e Análise dos Estudos Científicos Existentes}

O inventário sobre o conhecimento adquirido acerca do setor médio da PCRGS foi elaborado a partir das colaborações dadas por estudos pioneiros na pesquisa científica costeira do Sul do Brasil. Os estudos de Morris (1963), Delaney (1965), Martins (1967), Villwock (1972), Soliani Jr. (1973), Carraro et al. (1974) e Corrêa (1986) abriram as portas da compreensão sobre a geologia e geomorfologia da Província Costeira do RS, sendo as pesquisas de Villwock (1972 e 1984) dois grandes marcos referentes à compreensão científica dessa província.

Posteriormente, as caracterizações dos sistemas deposicionais referentes aos Leques Aluviais, às planícies lagunares e às barreiras arenosas da PCRGS feitas por Villwock e Tomazelli (1995 e 2007), Tomazelli et al. (1998) e Tomazelli e Villwock (2000) possibilitaram que esse arcabouço sobre o Litoral Médio do RS fosse ampliado, assim como dos demais setores da costa do Sul do Brasil. A formulação do modelo evolutivo da PCRGS, através das oscilações climáticas do Quaternário e das consequentes variações glacioeustáticas do nível médio do mar, proporcionou que a dinâmica natural da planície costeira mais 
meridional do Brasil fosse compreendida, possibilitando a aplicação desse modelo evolutivo generalizado para setores individuais do ambiente costeiro do RS.

O setor correspondente ao Litoral Médio, então, teve sua evolução particularmente compreendida a partir dos estudos de Dillenburg et al. (2000, 2003, 2004, 2005 e 2007) e Dillenburg e Hesp (2009), os quais identificaram a natureza transgressiva e, em alguns trechos, agradacional da barreira holocênica que contempla a área de estudo. Esses mesmos estudos identificaram a coexistência dessas duas tipologias evolutivas da barreira, sendo a primeira possuidora de um balanço negativo de sedimentos, com volumosos campos de dunas frontais e transgressivos desenvolvidos nessa região e que resultam de uma tipologia estacionária, como ocorre em Dunas Altas.

O desenvolvimento de um extenso campo eólico frontal e transgressivo nesse setor médio da barreira arenosa tipicamente erosivo foi analisado por Toldo Jr. et al. (2006) e Absalonsen e Toldo Jr (2007), juntamente com o fato de coexistirem trechos com balanço desigual de sedimentos na região. Ambos os estudos identificaram um "engarrafamento" do transporte sedimentar líquido, cuja resultante final é de sul para norte na costa do RS, ao sul de uma inflexão de $11^{\circ}$ do alinhamento costeiro localizada na região de Mostardas. Essa variação local no ângulo de orientação da linha de costa provoca, portanto, deposição de sedimentos e incremento do estoque sedimentar subaquoso nessa área, alimentando as dunas da região de Dunas Altas posteriormente.

Por fim, o compêndio de estudos acerca do ambiente natural do Litoral Médio do RS apresentou a configuração climática da região, sobre a qual Tomazelli (1990 e 1993), Tomazelli e Villwock (1991) e Tomazelli et al. (2000) desenvolveram análises acerca do regime de ventos local e geomorfologia eólica associada a ele, assim como foi realizado por Martinho et al. (2009) referente à relação entre pluviosidade e potencial local de transporte eólico. O estudo de Plá (2004) sobre o comportamento do regime de precipitação na região do PNLP, situado no Litoral Médio, também elevou o estado da arte do conhecimento científico da área de estudo, corroborando com a bibliografia existente acerca da importância dos centros de ação atmosféricos Frente Polar Atlântica e Anticiclone do Atlântico Sul na climatologia local.

\section{REFERÊNCIAS}

ABSALONSEN, L.; TOLDO Jr., E. E. A Influência da Inflexão Costeira na Variabilidade da Linha de Praia em Mostardas - RS. Pesquisas em Geociências 34 (1): 3-18, 2007.

BARLETTA, R. C. Efeito da Interação Oceano-Atmosfera sobre a Morfodinâmica das Praias do Litoral Central do Rio Grande do Sul, Brasil. 2000. Fundação Universidade Federal do Rio Grande, Rio Grande, Rio Grande do Sul, Dissertação de Mestrado. 
BARLETTA, R. C.; CALliARI, L. J. Detalhamento dos Aspectos Atmosféricos e Ondulatórios que Determinam as Características Morfodinâmicas das Praias do Litoral Central do Rio Grande do Sul. Anais do Simpósio Brasileiro de Praias Arenosas. Itajaí. 2000

CALLIARI, L. J.; KLEIN, A. H. F. Características Morfodinâmicas e Sedimentológicas das Praias Oceânicas entre

Rio Grande e Chuí, RS. Pesquisas em Geociências 20(1):48-56. 1993.

CARRARO, C. C.; GAMERMANN, N.; EICK, N. C.; BORTOLUZZI, C. A.; JOST, H.; PINTO, J. F. Mapa Geológico do Rio Grande do Sul. Escala 1:1000.000. Porto Alegre: UFRGS, 1974.

CORRÊA, I. C. S. Evidences of Sea Level Fluctuation in the Rio Grande do Sul Continental Shelf, Brazil. Quaternary of South America and Antartic Peninsula, Holanda 4: 237-247, 1986.

CORRÊA, I. C. S. Sedimentos Superficiais da Plataforma e Talude Continental do Rio Grande do Sul. Pesquisas em Geociências 19: 95-104, 1987.

CROWLEY, T. J.; NORTH, G. R. Paleoclimatology. Oxford Monographs on Geology and Geophysics , no. 18. Nova Iorque: Oxford University Press, 1991.

DELANEY, P. J. V. Fisiografia e Geologia de Superfície da Planície Costeira do Rio Grande do Sul. Publicação Especial da Escola de Geologia da UFRGS. Porto Alegre. 6: 1-195.

DILLENBURG. S. R.; ROY, P. S.; COWELL, P. J.; TOMAZELLI, L. J. Influence of Antecedent topography on Coastal Evolution as Tested by the Shoreface Translation-Barrier Model (STM). Journal of Coastal Research 16 (1): 71-81, 2000.

DILlEnBURG. S. R.; TOMAZELLI, L. J.; CLEROT, L. C. P. Gradients of Wave Energy as the Main Factor Controlling the Evolution of the Coast of Rio Grande do Sul in Southern Brazil during the Late Holocene. Coastal Sediments '03, 5, Clearwater Beach. Proceedings (CD-ROM). Regional Alongshore Variability of Shoreline Movements. 2003.

DILLENBURG, S. R.; TOMAZELLI, L. J.; BARBOZA, E. G. Barrier Evolution and Placer Formation and Bujuru, Southern Brazil. Marine Geology 203: 43-56, 2004.

DILlENBURG, S. R.; MARTINHO, C. T.; TOMAZELLI, L. J.; DORNELES, L.; SILVA, D. B. Gradientes de Altura de Ondas ao Longo da Costa do Rio Grande do Sul. Resumos do $\mathbf{1 0}^{\circ}$ Congresso da Associação Brasileira de Estudos do Quaternário - CD-ROM. 2005.

DILlENBURG, S. R.; BARBOZA, E. G.; TOMAZELLI, L. J.; de LIMA, L. G.; BECKER, L. E. G. A Barreira Costeira de Dunas Altas no Litoral Médio do Rio Grande do Sul: um exemplo de barreira agradacional ou 
estacionária. Resumos do $\mathbf{1 2}^{\mathbf{0}}$ Congresso da Associação Brasileira de Estudos do Quaternário. Disponível em: http://www.abequa.org.br/mostra_ano.php?ano=2007. 2007. Acesso em 2 de março de 2017.

DILlENBURG, S. R.; HESP, P. A. The Holocene Coastal Barriers of Rio Grande do Sul. Cap. 3. In: DILLENBURG, S. R.; HESP, P. A. Geology and Geomorphology of Holocene Coastal Barriers of Brazil. Heidelberg: Springer, p. 53-91, 2009.

HESP, P. A.; DILLENBURG, S. R.; BARBOZA, E. G.; TOMAZELLI, L. J.; AYUP-ZOUAIN, R. N.; ESTEVES, L. S.; GRUBER, N. L. S.; TOLDO Jr, E. E.; TABAJARA, L. L; CLEROT, L. C. P. Beach Ridges, Foredunes or Transgressive Dunefields? Definitions, Initiation and an examination of the Itapeva to Tramandaí Barrier System. Anais da Academia Brasileira de Ciências 7(3): 493-508. 2005.

MARCHI DA MOTTA, L.; TOLDO Jr., E. E.; DE SÁ, L. E.; DE ALMEIDA, B.; NUNES, J. C. Sandy Sediment Budget of the Midcoast of Rio Grande do Sul, Brazil. Journal of Marine Research 73: 49-69, 2015.

MARTINHO, C. T.; DILlENBURG, S. R.; HESP, P. A. Wave Energy and Longshore Sediment Transport Gradients Controlling Barrier Evolution in Rio Grande do Sul, Brazil. Journal of Coastal Research 25: 285-293, 2009.

MORRIS, R. H. Geologia Geral das Quadrículas de Gravataí, Taquara e Rolante, Rio Grande do Sul, Brasil. Publicação Especial da Escola de Geologia da UFRGS. Porto Alegre. 5:1-37. 1963.

PLÁ, R. G. O Regime de Precipitação no Parque Nacional da Lagoa do Peixe, RS. Trabalho de Graduação em Geografia da UFRGS. Porto Alegre: UFRGS, 2004.

SOLIANI JR, E. Geologia da Região de Santa Vitória do Palmar, RS, e a Posição Estratigráfica dos Fósseis de Mamíferos Pleistocênicos. Dissertação de Mestrado em Geociências da UFRGS. Porto Alegre: UFRGS, 1973.

TOLDO Jr., E. E.; ALMEIDA, L.; NICOLODI, J.; ABSALONSEN, L.; GRUBER, N. L. S. O Controle da Deriva Litorânea no Desenvolvimento do Campo de Dunas e da Antepraia no Litoral Médio do Rio Grande do Sul. Pesquisas em Geociências 33: 35-42. 2006.

TOMAZELLI, L. J. Contribuição ao Estudo dos Sistemas Deposicionais Holocênicos do Nordeste da Província Costeira do Rio Grande do Sul - com ênfase no sistema eólico. Tese de Doutorado em Geociências da UFRGS. Porto Alegre: UFRGS, 1990.

TOMAZELLI, L. J.; VILLWOCK, J. A. Geologia do Sistema Lagunar Holocênico do Litoral Norte do Rio Grande do Sul, Brasil. Pesquisas em Geociências 18 (1): 13-24, 1991.

TOMAZELLI, L. J. O Regime de Ventos e a Taxa de Migração das Dunas Eólicas Costeiras do Rio Grande do Sul, Brasil. Pesquisas em Geociências 20 (1): 18-26, 1993. 
TOMAZELLI, L. J. VILLWOCK, J. A.; DILLENBURG, S. R.; BACHI, F. A.; DEHNHARDT, B. A. Significance of Present Day Coastal Erosion and Marine Transgression, Rio Grande do Sul, Southern Brazil. Anais da Academia Brasileira de Ciências 70(2): 221-229. 1998.

TOMAZELLI, L. J.; VILLWOCK, J. A. O Cenozoico do Rio Grande do Sul: geologia da planície costeira. In: HOLZ, M. DE ROS, L. F. (eds.) Geologia do Rio Grande do Sul. Edições CIGO/UFRGS. Porto Alegre, 2000. p. 375-406.

VILLWOCK. J. A. Contribuição à Geologia do Holoceno da Província Costeira do Rio Grande do Sul. Dissertação de Mestrado em Geociências da UFRGS. Porto Alegre: UFRGS, 1972.

VILLWOCK, J. A. Geology of Coastal Province of Rio Grande do Sul, Southern Brazil: a synthesis. Pesquisas em Geociências 16: 5-49, 1984.

VILLWOCK, J. A.; TOMAZELLI, L. J. Geologia Costeira do Rio Grande do Sul. Notas Téenicas 8: 1-45. 1995.

VILLWOCK, J. A.; TOMAZELLI, L. J. Planície Costeira do Rio Grande do Sul: gênese e paisagem atual. In: Biodiversidade: regiões da lagoa do Casamento e os butiazais de Tapes, Planície Costeira do Rio Grande do Sul. Ministério do Meio Ambiente. Brasília/DF. Disponível em: www.mma.gov.br. 2007. Acesso em 4 de março de 2017. 